\title{
Antipsychotic dose: from research to clinical practice
}

\author{
Robert Chaplin and Sean McGuigan
}

\begin{abstract}
A case note study of antipoychotic prescribing in on inner London hospltal showed that atthough doess of inclividuat drugs were bolow the Brtitsh National Formulary limits, polypharmacy occurred in a third of cases. Multiple regrestion anctysts showed high doses were cassoclated with a current risk to the self or others and increasing number of provious admisations in patients with mania and treatiment non-responstveness in schlzophrenia.
\end{abstract}

Recent interest surrounds the establishment of optimum antipsychotic doses in the treatment of psychosis. In their Consensus Statement on the Use of High Dose Antipsychotics, the Royal College of Psychiatrists (Thompson, 1994) addressed the dangers of exceeding the maximum recommended doses. In a comment on the statement, Kane (1994) concluded that doses above the equivalent of $15-20 \mathrm{mg}$ of haloperidol (500-700 mg chlorpromazine) offered no advantage in the treatment of schizophrenic patients without a history of treatment refractoriness, while McEvoy et al (1991) stated that the median effective dose is $350 \mathrm{mg}$ chlorpromazine equivalents per day. There is no systematic research that supports the value of high doses or polypharmacy.

The aims of this study were to document the patient characteristics associated with prescribed antipsychotic dose and, compare these doses with research into optimum dose regimes in the treatment of psychosis.

\section{The study}

All patients in the acute wards of Springfield psychiatric hospital, London, who were receiving regular antipsychotic medication were studied during a one month period in 1994. Case notes were examined to obtain data on sociodemographic detalls, diagnoses and history. This was supplemented, where necessary, by a brief discussion with the nurse in charge or the junior psychiatrist. Ward staff had no opportunity to modify prescribing. The current daily antipsychotic dose in $\mathrm{mg} /$ day chlorpromazine equivalents was calculated according to the method of Foster (1989). Six patients receiving only risperidone, for which there is no data on chlorpromazine equivalent dosage, were excluded from the analysis.

A psychiatric diagnosis was made from the information available in the case notes. Three diagnostic groups were formed: schizophrenia (including schizoaffective disorder, paranoid psychosis and other non-affective psychoses), mania (including mixed affective disorder), and 'other'. The broad classification of schizophrenia was used for comparison with studies of optimum antipsychotic dose.

\section{Findings}

The 107 patients currently recetving regular antipsychotic prescriptions are described in Table 1. Of the $67(63 \%)$ of patients on single antipsychotic drugs, diagnoses were: 49 (73\%) schizophrenia, 11 (16\%) mania, and seven (11\%) 'other'. Forty (37\%) were prescribed two or more antipsychotics, four (4\%) recetving three antipsychotics. Of those receiving multiple antipsychotic prescriptions, $36(90 \%)$ suffered from schizophrenia and four (10\%) mania.

Other psychotropic drugs additionally prescribed regularly to the sample included benzodiazepines (10 patients), lithium (19 patients), anticonvulsants (seven patients) and antidepressants (13 patients). Those with schizophrenia or mania who were additionally prescribed lithium or an anticonvulsant recetved a median dose of $1000 \mathrm{mg}$ chlorpromazine equivalents and the three patients prescribed benzodiazepines recetved a median dose of $1900 \mathrm{mg}$.

Using multiple regression analysis, the doses in chlorpromazine equivalents prescribed to men (median $847 \mathrm{mg} /$ day) and women (median $666 \mathrm{mg} /$ day) were not significantly different. Patients with schizophrenia (median dose of $848 \mathrm{mg}, 50 \%$ interquartile range $500-1250 \mathrm{mg})$ and those with mania (median dose $800 \mathrm{mg}, 50 \%$ interquartile range $550-1200 \mathrm{mg}$ ), recetved strikingly similar doses but those with other diagnoses (most frequently depresstve disorder) recetved a significantly lower dose (median $300 \mathrm{mg}$ ).

Within each diagnostic group an attempt was made using multiple regression analysis to model 
the variation of the antipsychotic dose in chlorpromazine equivalent with a range of sociodemographic and clinical factors. The multiple regression models proposed were of the form:

$$
\text { antipsychotic dose }=\alpha+\Sigma \beta_{1} X_{1}
$$

where $X_{1}$ represented the variables age, gender, ethnicity, history of violence, risk of self-harm. risk of harm to others, Mental Health Act status, drug or alcohol history, acute disturbance, treatment unresponstveness and number of previous admissions. In those with schizophrenia, the only variable with which higher antipsychotic dose was significantly associated at the 5\% level was a history of treatment unresponstveness. In those with mania, higher antipsychotic dose was significantly associated with a current risk to the self or others, and increasing numbers of previous admissions.

High dose antipsychotic was defined as $>1000 \mathrm{mg}$ chlorpromazine equivalent per day and was prescribed to $34(41 \%)$ patients with schizophrenia, $6(37.5 \%)$ patients with mania but to none of those with other diagnoses. Only one patient was prescribed a single drug at higher dose than recommended by the British National Formulary (BNF; British Medical Association and Royal Pharmaceutical Society of Great Britain, 1993). A separate univariate analysis was used to examine the characteristics of the patients with schizophrenia recetving high dose antipsychotics. This was strongly associated with a history of violence $\left(\chi^{2}=8.41\right.$, d.f. $\left.=1, P=0.004\right)$, and a mental state characterised by a risk of self-harm, harm to others or severe disturbance $\left(\chi^{2}=4.91\right.$, d.f. $=1$, $P=0.027$.

\section{Comments}

This study shows that the guidelines in the Royal College Consensus Statement are being adhered to with regard to the use of individual antipsychotic drug doses within the maximum limits set by the BNF. However, antipsychotic polypharmacy occurred in nearly a third of all patients, and as a result high doses $(>1000 \mathrm{mg}$ chlorpromazine equivalents) were prescribed to $40 \%$ of patients with diagnoses of schizophrenia and mania.

The factors that predicted high dose prescribing can be divided into two groups. First, those that were prescribed for their sedative effects in patients suffering from schizophrenia with acute disturbance or a history of violence, and in patients with mania at risk of harming themselves or others. This suggests they are used in preference to benzodiazepines which were only regularly prescribed to $10 \%$ of the sample. Additionally, this cross-sectional data suggests that the use of other agents (e.g. mood stabilisers
Table 1. Patient characteristics and antipsychotic drug prescriptions

\begin{tabular}{|c|c|c|}
\hline Patient charactertatics & $\begin{array}{l}\text { Mols } \\
(n-66)\end{array}$ & $\begin{array}{l}\text { Fomole } \\
(n=41)\end{array}$ \\
\hline $\begin{array}{l}\text { Age: Mean (s.d.) } \\
\text { Compulsory status (\%) } \\
\text { Treatment unresponstve } \\
\text { History of violence } \\
\text { Current alcohol or drug } \\
\text { use }\end{array}$ & $\begin{array}{l}35 \text { years (15) } \\
36(55 \%) \\
14(21 \%) \\
26(39 \%) \\
16(24 \%)\end{array}$ & $\begin{array}{l}44 \text { years (16) } \\
23(51 \%) \\
13(31 \%) \\
3(7 \%) \\
2(5 \%)\end{array}$ \\
\hline $\begin{array}{l}\text { High dose prescriptions, } \\
>1000 \mathrm{mg} / \mathrm{CPZ} \text { daily }\end{array}$ & $25(40 \%)^{\circ}$ & $13(33 \%)^{\circ}$ \\
\hline \multicolumn{3}{|c|}{$\begin{array}{l}\text { Medion doee of total ontipsychotic druges (mg CPZ } \\
\text { equivalent) }\end{array}$} \\
\hline $\begin{array}{l}\text { Total (50\% interquartile } \\
\text { range) } \\
\text { Schizophrenia }\end{array}$ & $\begin{array}{l}847 \mathrm{mg} \\
(500-1250) \\
967 \mathrm{mg} \\
(n=54)\end{array}$ & $\begin{array}{l}666 \mathrm{mg} \\
(375-1100) \\
720 \mathrm{mg} \\
(n=29)\end{array}$ \\
\hline Mania & $\begin{array}{l}733 \mathrm{mg} \\
(n=8)\end{array}$ & $\begin{array}{l}950 \mathrm{mg} \\
(n=8)\end{array}$ \\
\hline Other diagnoses & $\begin{array}{l}267 \mathrm{mg} \\
(n=3)\end{array}$ & $\begin{array}{l}300 \mathrm{mg} \\
(n=5)\end{array}$ \\
\hline
\end{tabular}

-Excludes those prescribed isperidone as no data available on relative antipsychotic potency in $\mathrm{mg}$ chlorpromazine equivalents.

$\mathrm{CPZ}$, chlorpromazine

and benzodiazepines) is not associated with lower dose antipsychotic prescribing.

The other important indicator of high dose prescription was lliness with a poor outcome. Measures of chronicity in patients with mania (increasing number of admissions) and treatment resistance in patients with schizophrenia were associated with increased prescribed dose. Alternative strategies for the management of treatment resistance (Royal College of Psychiatrists, 1994) include review of diagnosis and compliance, dose reduction, clozapine (only used in 3\% of our sample despite $27 \%$ being treatment resistant), augmentation with mood stabilising drugs where appropriate, and re-evaluation of environmental stressors.

This study has addressed the patient characteristics associated with the receipt of high dose antipsychotic drugs but is of limited value in explaining the therapeutic rationale behind such decisions. Further studies are needed to invest1gate the attitudes of psychiatrists to the use of high dose antipsychotics and polypharmacy.

\section{Conclusion}

Patients are frequently prescribed higher doses of antipsychotics than supported by research findings, even though keeping within safe BNF limits. High dose treatment arises from polypharmacy and carries increased risk of toxic effects, for 
example Parkinsonism and akathisia, with subsequent risk of non-compliance and limited evidence of therapeutic advantage. It is recommended that psychiatrists reduce polypharmacy, consider alternative options for treatment refractory patients, attempt careful dose reductions in patients receiving high doses and locally audit their antipsychotic prescribing practices.

\section{Acknowledgement}

We are grateful to Dr Mark Potter for his help in the preparation of this paper.

\section{References}

Brmish Medical association and Royal Pharmaceutical SOCIETY OF GREAT BRTTAN (1993) British National Formulary, no. 26. Bath: The Bath Press.

FOSTER, P. (1989) Neuroleptic equivalence. The Pharmaceutical Journal. September 30, 431-432.
KANE, J. M. (1994) The use of higher dose antipsychotic medication: Comment on the Royal College of Psychlatrists consensus statement. British Journal of Psychiatry, 164, 431-432.

McEvoY, J. P., HogARTY, G. E. \& STEINGaRD, S. (1991) Optimal dose of neuroleptic in acute schizophrenia. A controlled study of the neuroleptic threshold and higher haloperidol dose. Archives of General Psychiatry. 48. $739-745$.

The Royal College of Psychlatrists: Thompson, C. (1994) Consensus statement on the use of high dose antipsychotic medication. British Joumal of Psychiatry. $164,448-458$.

* Robert Chaplin, Senior Registrar in Psychiatry, St. George's Hospital Medical School, Cranmer Terrace, London SW17 ORE, and Sean McGuigan, Formerly Head of Biostatistics Department, Department of Mental Health Sciences, St. George's Hospital Medical School

*Correspondence

\section{Management for Psychiatrists}

\section{Second Edition}

\section{Edited by Dinesh Bhugra and Alistair Burns}

Since the last edition rapid changes in the NHS have meant that clinicians have had even less time to manage change and keep up to date with health reforms. For this new edition, all the existing material has been extensively revised. In addition, eight new chapters have been added, including a section on changes and conflicts covering large areas of potential difficulty that clinicians may have to deal with.

As before, the emphasis is on how to get the best for and from services. Practical advice is given on management. Negotiation techniques and time and stress management are also covered.

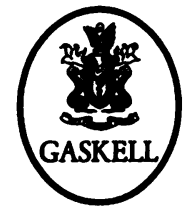
$£ 20.00 \bullet 360$ pp. $\bullet 1995 \bullet$ ISBN 0902241850
Available from bookshops and from the Publications
Department, Royal College of Psychiatrists, 17 Belgrave Square,
London SW1X 8PG (Tel. 0171-235 2351 extension 146) 